\title{
Development of Improved Graphical Displays for an Advanced Outage Control Center, Employing Human Factors Principles for Outage Schedule Management
}

\author{
Shawn St. Germain \\ Ronald Farris \\ Ken Thomas
}

September 2015

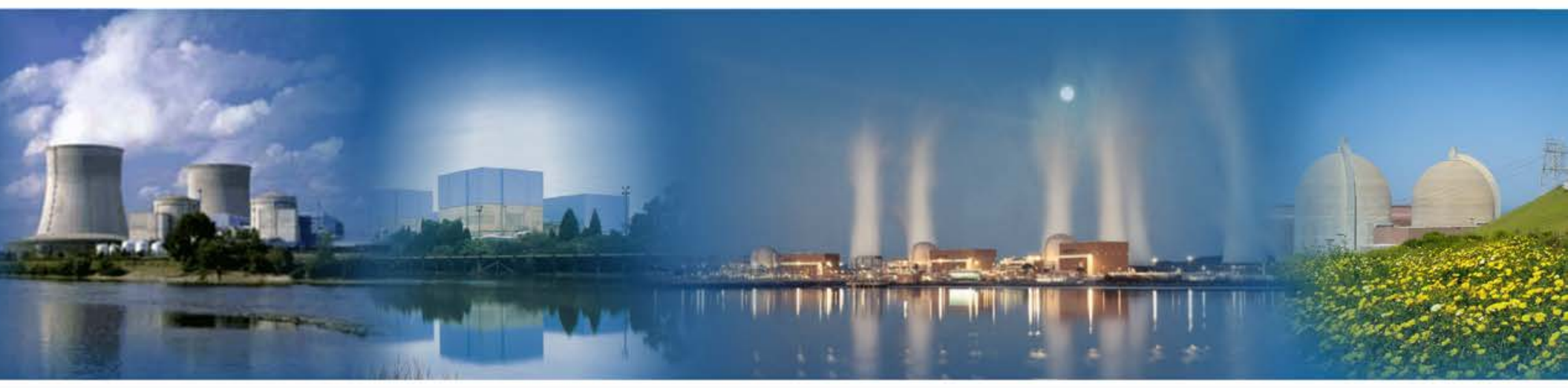

The INL is a U.S. Department of Energy National Laboratory operated by Battelle Energy Alliance 


\section{DISCLAIMER}

This information was prepared as an account of work sponsored by an agency of the U.S. Government. Neither the U.S. Government nor any agency thereof, nor any of their employees, makes any warranty, expressed or implied, or assumes any legal liability or responsibility for the accuracy, completeness, or usefulness, of any information, apparatus, product, or process disclosed, or represents that its use would not infringe privately owned rights. References herein to any specific commercial product, process, or service by trade name, trade mark, manufacturer, or otherwise, does not necessarily constitute or imply its endorsement, recommendation, or favoring by the U.S. Government or any agency thereof. The views and opinions of authors expressed herein do not necessarily state or reflect those of the U.S. Government or any agency thereof. 


\title{
Development of Improved Graphical Displays for an Advanced Outage Control Center, Employing Human Factors Principles for Outage Schedule Management
}

\author{
Shawn St. Germain \\ Ronald Farris \\ Ken Thomas
}

September 2015

\author{
Idaho National Laboratory \\ Idaho Falls, Idaho 83415 \\ http://www.inl.gov
}
Prepared under Work Package L-12N060305
Prepared for the
U.S. Department of Energy
Office of Nuclear Energy
Under DOE Idaho Operations Office
Contract DE-AC07-05ID14517





\section{EXECUTIVE SUMMARY}

This research effort is a part of the Light Water Reactor Sustainability (LWRS) Program, which is a research and development (R\&D) program sponsored by the Department of Energy. The LWRS Program is performed in close collaboration with industry $R \& D$ programs that provide the technical foundations for licensing and managing the long-term, safe, and economical operation of current nuclear power plants (NPPs). The LWRS Program serves to help the United States (U.S.) nuclear industry adopt new technologies and engineering solutions that facilitate the continued safe operation of these NPPs and extension of their current operating licenses.

The long-term viability of existing NPPs in the U.S. depends on a number of factors, including maintaining high capacity factors; maintaining nuclear safety; and reducing operating costs, particularly those associated with refueling outages. Refueling outages typically take 20 to 30 days, and for existing light water NPPs in the U.S., the reactor cannot be in operation during the outage. Furthermore, given that many NPPs generate between $\$ 1$ million/day to $\$ 1.5$ million/day in revenue when in operation, there is considerable interest in shortening the length of refueling outages. Yet refueling outages are highly complex operations, involving multiple concurrent and dependent activities that are somewhat challenging to coordinate; therefore, finding ways to improve refueling outage performance, while maintaining nuclear safety, has proven to be difficult.

The Advanced Outage Control Center (OCC) (AOCC) Project is an R\&D demonstration activity under the LWRS Program. A goal of the LWRS AOCC Project is to improve the management of commercial NPP refueling outages. To accomplish this goal, Idaho National Laboratory (INL) is developing an AOCC that is specifically designed to maximize the usefulness of communication and collaboration technologies for outage coordination and problem resolution activities. The overall focus is on developing an AOCC with the following capabilities that enable the NPP and OCC staff to:

- Collaborate in real-time to address emergent issues

- Effectively communicate outage status to all workers involved in the outage

- Effectively communicate discovered conditions in the field to the OCC

- Provide real-time work status

- Provide automatic pending support notifications

- Provide real-time requirements monitoring

- Maximize their collective situational awareness to improve decision-making

- Leverage macro data to better support resource allocation.

INL has partnered with several commercial NPP utilities to develop a number of advanced outage management technologies. These outage management technologies have focused on both collaborative technologies for OCCs and developing mobile technologies for NPP field workers.

This report describes recent efforts made in developing a suite of outage technologies to support more effective schedule management. Currently, a master outage schedule is created months in advance using the NPP's existing scheduling software (e.g., Primavera P6). Typically, during the outage, the latest version of the schedule is printed at the beginning of each shift. INL and its partners are developing technologies that will have capabilities such as automatic schedule updating, automatic pending support notifications, and the ability to allocate and schedule outage support task resources on a sub-hour basis (e.g., outage micro-scheduling). This report also describes the scheduling challenges that occur during outages, how the outage scheduling technologies INL is developing help address those challenges, and the latest developments on this task (e.g., work accomplished to date and the path forward). 


\section{ACKNOWLEDGMENTS}

The Advanced Outage Control Center research team would like to acknowledge the efforts of the following individuals and organizations that made this research possible:

- Michael Grigsby, Carlos Williams, and members of the Arizona Public Services Palo Verde Nuclear Generating Station staff for hosting the research activities.

- Ken Thomas and Dr. Bruce Hallbert for technical review of the research methodology.

- Josh Bartlett for his assistance in developing the dynamic schedule monitoring displays. 


\section{CONTENTS}

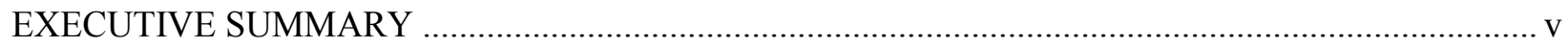

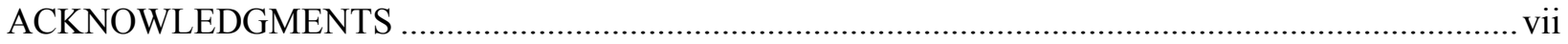

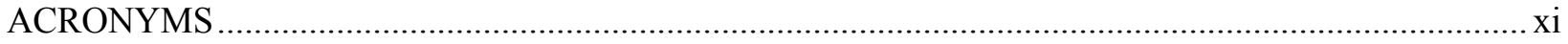

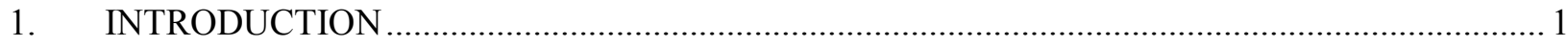

2. CURRENT METHOD OF SCHEDULE MANAGEMENT ….................................................. 3

3. CAPABILITIES AFFORDED THROUGH USE OF ELECTRONIC WORK PACKAGES ........... 5

4. HUMAN FACTORS PRINCIPLES RELATED TO OVERVIEW DISPLAYS ............................ 7

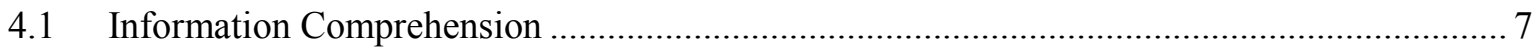

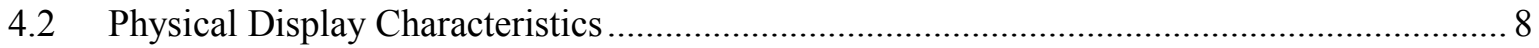

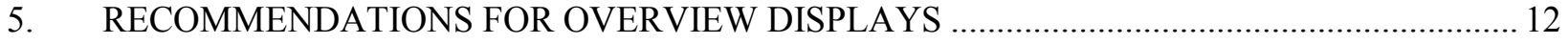

5.1 General Recommendations for Electronic Displays ........................................................ 12

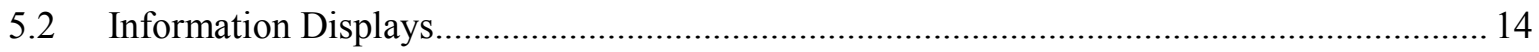

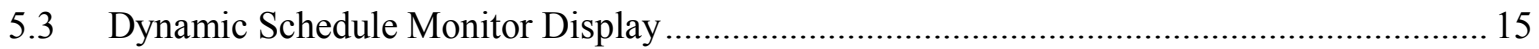

5.4 Overview Display for Work Completion Metrics................................................................ 20

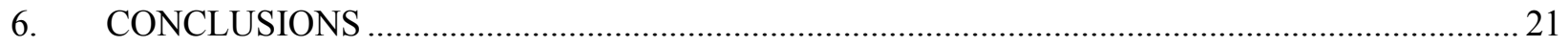

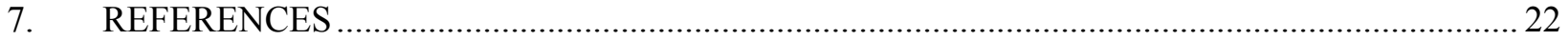

\section{FIGURES}

Figure 1. Function allocation analysis table, "current" function allocation illustration............................. 10

Figure 2. Function allocation analysis table, "desired" function allocation illustration. .......................... 11

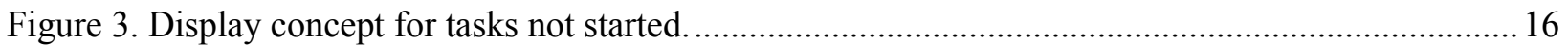

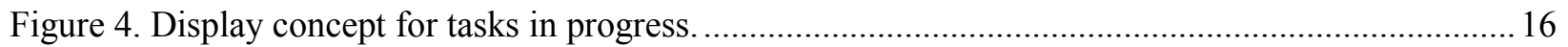

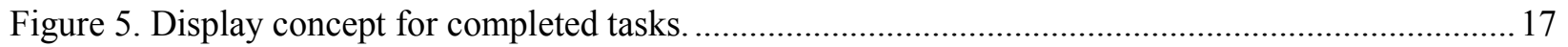

Figure 6. Field workers using electronic work package at Palo Verde................................................... 18

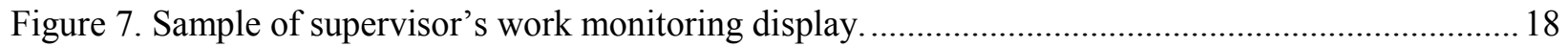

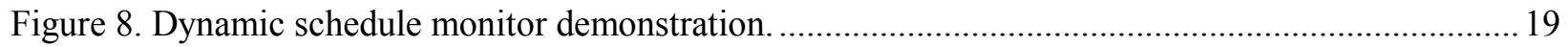

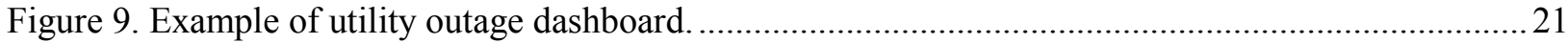




\section{ACRONYMS}

AOCC Advanced Outage Control Center

AWP automated work package

CBP computer-based procedure

EWP electronic work package

FA function allocation

HFE human factors engineering

HSI human-systems interface

INL Idaho National Laboratory

LWRS Light Water Reactor Sustainability

NPP nuclear power plant

OCC Outage Control Center

QC quality control

R\&D research and development

RAS Resource Allocation Software

U.S. United States 


\section{INTRODUCTION}

This research effort is a part of the Light Water Reactor Sustainability (LWRS) Program, which is a research and development program sponsored by the Department of Energy. The LWRS Program is performed in close collaboration with industry research and development programs that provide the technical foundations for licensing and managing the long-term, safe, and economical operation of current nuclear power plants (NPPs). The LWRS Program serves to help the United States nuclear industry adopt new technologies and engineering solutions that facilitate the continued safe operation of these NPPs and extension of the current operating licenses.

One key research pathway in the LWRS Program is the advanced instrumentation, information, and control research pathway. The purpose of this research pathway is to enable modernization of legacy instrumentation, information, and control systems in a manner that (a) creates a seamless digital environment encompassing all aspects of NPP operations and support; and (b) builds a three-dimensional information architecture that integrates NPP systems, processes, and workers in an array of interconnected technologies. Within this pathway, a number of pilot projects are being conducted as a means for industry to collectively integrate these new technologies into NPP work activities.

One major area selected for research into enabling capability is outage safety and efficiency. This pilot project, "Advanced Outage Control Center (OCC) (AOCC)," is a multi-year effort targeted at NPP outage improvement. The primary purpose of this pilot project is to improve management of NPP outages through development of an AOCC that is specifically designed to maximize the usefulness of communication and collaboration technologies for outage coordination and problem resolution activities.

NPP refueling outages are some of the most challenging periods that utilities face, in both tracking and coordinating thousands of activities in a short span of time, usually between 20 to 30 days. Outage work requires a large supplemental workforce, including hundreds of contract personnel, which increases the complexity of communication and information flow. Other challenges, including work sequencing, work group coordination, nuclear safety concerns arising from atypical system configurations, and resource allocation issues, can create delays and schedule overruns, driving up overall outage costs.

The current technologies employed at most NPPs to communicate critical information are slow, inaccurate at times, and rely on the physical presence of outage staff and key personnel to obtain and validate critical system and work progress status information. Today, the majority of outage communication is done using processes and technologies that do not take advantage of advances in modern communication technology. Some common communication practices include runners that deliver paper-based requests for approval, radios, landline telephones, email, desktop computers, daily printouts of the schedule, and static whiteboards that are used to display information. There are large amounts of static information displayed and the information requires regular evaluation to determine its validity. These current processes for controlling information are also labor intensive, and as NPPs attempt to reduce staff, these manual and disconnected processes have potential to become more difficult to manage. The current methods of displaying and tracking information will likely be inadequate to process the increased use of real-time information that will be available with the growing use of handheld mobile technology, automated work packages (AWPs) (also known as electronic work packages [EWPs]), computer-based procedures (CBPs), or computer programs that passively track work completion and readiness. In general, the commercial nuclear industry has not yet taken full advantage of advancements in modern mobile technologies that enable communication, collaboration, real-time data streaming, and information sharing to and from the field.

Discussions with outage experts across the industry have identified areas of need that will have the biggest return on investment. It has become clear to the research staff that communication and collaboration technologies could be used to improve schedule management, resource allocation, and emergent issue response. This report focuses on recent efforts made in developing a suite of outage technologies to support more effective schedule management. The most common approach is for a utility 
to develop a master outage schedule months in advance using the NPP's existing scheduling software (e.g., Primavera P6). Typically, during the outage, the latest version of the schedule is printed at the beginning of each shift. Idaho National Laboratory (INL) and its partners are developing technologies that will have capabilities such as automatic schedule updating, automatic pending support notifications, and the ability to allocate and schedule outage support task resources on a sub-hour basis (e.g., outage micro-scheduling). This report also describes the scheduling challenges that occur during outages, how the outage scheduling technologies that INL is developing help address those challenges, and the latest developments on this task (e.g., work accomplished to date and the path forward).

Previous INL reports have described various advanced outage functions that will become available through application of technology. These advanced functions are described here as they will be leveraged in new schedule monitoring tools or graphics. Technology improvements can enable AOCC functions that include, but are not limited to:

- Real-Time Collaboration for Emergent Issues - Using multi-touch monitors and high-quality audio and video conferencing equipment deployed in various coordination centers, staff can simultaneously work on complex problems by sharing real-time pictures, diagrams, schedule information, and notes. This technology also facilitates communicating the product(s) of the collaboration effort to the OCC, subject matter experts, managers, or other stakeholders. An electronic record of the resolution of the issue assists in knowledge management and future use of the information. The use of communication technologies has potential to reduce the need for face-to-face meetings, saving time, and the richer data may increase the level of comprehension of complex problems.

- Real-Time Work Status - The use of CBPs and AWPs allows the OCC staff instant status of work packages and procedures. These systems also allow outage managers to call up and view the actual steps of a work package or procedure as they are completed or to simply notify the OCC automatically when certain activities, tasks, or subtasks are completed. When tied into scheduling software, CBPs and AWPs provide a real-time picture of schedule adherence. Portable wireless cameras installed near critical job sites that feed to the OCC also allow outage managers to remotely monitor job status without relying on field workers to call in status updates, thus allowing them to focus on work completion with little or no interruption that ultimately should reduce the time required to complete the task.

- Automatic Pending Support Notifications - Utilizing embedded triggers in CBPs and AWPs, notifications to support staff can be automatically routed to required personnel via calendar, text, or email notifications at predetermined points in the work process, alerting them of pending tasking that requires their support. For example, a trigger may be set 30 minutes prior to a quality control (QC) hold point, notifying the assigned QC inspector of the upcoming required inspection. If the first resource (QC inspector) is unable to provide support in a reasonable time frame, the first resource would reject the notification and a follow-on notification would go to the next resource, and so on until a resource (QC inspector) accepts it. Automated notifications allow the staff to perform more efficient resource allocation and real-time planning.

- Improved Communication of Discovered Conditions from the Field — Using mobile technologies, field workers who identify issues in the field can set up an instant video conference with the OCC or a supervisor in the field at the point of the problem. This would provide the OCC staff with eyes on the issue and an instant understanding of the nature of the issue. It would also allow further interaction between outage managers and the person discovering the issue without having to physically go to the location. Further interaction may include directing the worker to send back additional video footage or an annotated photograph of the surrounding area or component or more carefully describing some aspect of the problem while providing a live-video feed. This also provides an opportunity for the OCC to pull in other stakeholders in real-time to make decision-making a more parallel process 
versus a series process saving all involved significant time and physical effort. Other benefits are realized such as reduced radiation exposure, reduced exposure to physical hazards, efficiency, and overall safety of not have numerous staff entering the NPP to put eyes on the issue. Another advantage to remote collaboration is the ability for decision-makers who are not on site (e.g., at corporate headquarters on business travel, or at home) to view the issue and make the necessary decision(s) without returning to the site to do so.

- More Efficient Dissemination of Information from the OCC - Utilizing advanced conferencing software and large multi-touch monitors, OCC managers can establish interactive status briefings in which stakeholders may participate from any location, onsite or offsite, using a variety of devices, including desktop computers, laptops, smart phones, and tablet computers. This anywhere/anytime capability should produce significant gains in efficiency and accuracy in communications.

- Real-Time Requirements Monitor-Utilizing a combination of information pulled from the status of CBPs and AWPs, real-time NPP status from the NPP computer, and NPP logs, OCC managers can more effectively and easily display status and readiness for key activities or tasks. These displays enable rapid analysis of state and status and expedite decision-making.

- Mobile Alerts - Utilizing a messaging system similar to instant messaging used by most smart phones, OCC managers could update NPP personnel when important milestones are met or NPP conditions change. For example, the system could provide alerts for events such as window closures, NPP risk level changes, protected system changes, or industrial or radiological hazards. These messages would consist of a simple statement of the condition, but also provide more detailed information for events that require it through use of an information icon. These messages could also be sent to handheld devices, desktop computers, and large screen displays throughout the NPP. This process would be much more effective and efficient than providing out-of-date information on static displays or printed material currently used at NPPs.

\section{CURRENT METHOD OF SCHEDULE MANAGEMENT}

Many outage activities are difficult to schedule with a high level of precision using technology that is currently deployed at NPPs. This is because the activities require introduction of additional task support resources at fixed points in their progression. Examples of when additional task support resources are introduced into a primary outage task include QC hold-point inspections, required operator actions during a maintenance activity, and temporarily lifting safety tags to support testing during maintenance (e.g., stroking a valve). Given the technologies currently in use, it is virtually impossible to precisely schedule these additional task support resources because the exact time depends on the work progress of the primary activity, which can have numerous variables that impact the work progress. Additionally, work planners typically create work packages significantly before the outage schedulers create the outage schedule. Often there is a disconnect between schedule activities and sections of the work packages. There is often not a clear link between the work management software tools and scheduling tools.

This creates a difficult resource allocation problem for these task support resources in that they must react quickly to a moving start time, based on the progress of the primary outage activity. For critical path activities, resources are sometimes deployed early so they are immediately available when needed. This creates a lot of unproductive wait time for these expensive task support resources. For noncritical path activities, they rely on an early warning notification from the OCC or job supervisor to be ready at a certain time. If subsequent delays exist in the primary activity, unproductive wait time and concurrent demands that are greater than what a given task support resource can meet are additional delays until the primary activity is accommodated in prioritized sequence. The OCC staff typically employs frequent meetings to ensure proper coverage of critical work. These frequent meetings consume many man-hours of critical OCC decision-maker's time. 
Furthermore, even if allocation of these support resources is resolved to the general satisfaction of the parties involved, there is no assurance that they were allocated in a manner that produced the most effective overall outage schedule progress. The reason is that the task of managing this real-time resource allocation problem is typically handled in the OCC in a "silo' $d$ " manner. That is, a coordinator in the OCC for each type of resource (e.g., reactor protection coverage, safety tagging, and QC) manages that resource independently, often without full awareness of how other coordinators are managing their resources. While the coordinator generally assigns support resources based on the known schedule priorities (e.g., the current critical path), it is a non-optimized solution. In general, this is because no one coordinator can predict the total schedule impact of delaying certain activities. Typically, the schedule is published once or twice per day. Deviations to the published schedule are tracked manually, and often different groups have a different picture of the impact of schedule disruptions. This is true when combined with other work delays that a given activity might experience. It is often seen in retrospect that resources were allocated to the wrong activities, and that a near critical path activity moved onto the critical path because of the cascading effect of multiple delays.

Even for bulk work (e.g., general valve maintenance) that is not "near critical path," general schedule creep tends to occur because of small delays in the activities themselves, or availability of required task support resources. This schedule creep phenomenon for bulk schedule activities is well known to outage managers and typically monitored with "burn-down curves." These delays create a "bow wave," where task support resources are needed near the end of the work windows for these routine outage activities (e.g., where mode changes define work windows, system drains/fills, and train/division swaps). At this point, the bow wave overwhelms certain task support resources such as the clearing of tags at a system level, running operational tests, and/or realigning systems. This is one typical way that routine bulk outage activities impact the critical path. In some cases, this bulk work actually becomes the critical path.

From the OCC's perspective, work can then be divided into two primary categories with respect to how it is tracked and monitored:

- First Category - Includes all work on "critical path" or "near critical path." The OCC normally tracks this work by updating waterfall schedules displayed in the OCC on large printouts. These printouts are marked up (updated with status) with markers and highlighters and reprinted when the schedule is updated. The OCC carefully monitors each scheduled activity and works with representatives from all involved groups to ensure handoffs are effective. Status updates for the work displayed on the schedule are usually a manual process that involves phone calls, face-to-face communications, and routine status updates from shop supervisors. When schedule deviations occur, the impact on subsequent work must be manually accessed and communicated to the affected work groups.

- Second Category - Includes the bulk work described earlier. This bulk work is usually managed through metrics related to the total number of activities scheduled and completed and associated man-hours of labor related to this work. Each station has its own measures of expected productivity related to the number of activities, and these measures might not be comparable between NPPs as the level of detail of their scheduled activities may be different. This method of monitoring bulk work completion (burn down) has significant limitations as a 15-minute activity is credited the same as an activity that may take 8 hours to complete. A shop supervisor may try to improve the performance indicators by pulling ahead smaller jobs, leaving the remaining work with a disproportionate level of longer duration activities that cannot be completed in the assigned window.

In summary, the optimized allocation of outage task support resources is impaired by the:

- Ability of outage coordinators to accurately predict the exact time in the outage schedule that a support task will be needed at a precision of a fraction of an hour.

- Ability to have real-time, efficient communications from the job site in apprising the OCC of small 
gains or delays in the work progress affecting the timing of allocation of task support resources.

- Inability to compute the combined effect of real-time progress gains or losses for a given activity with the competing needs for task support resources from multiple primary activities.

- Inability to optimize limited task support resources in consideration of the total outage impact. Automatic allocation to critical path activities might not be the best decision if a critical path activity has some flexibility in the sequence of tasks.

- Inability to accurately calculate burn down of bulk work and resources required to support it.

- Inability to quickly redirect task support resources in view of major schedule upsets (e.g., emergent critical work, and significant schedule delay in the critical path activity).

\section{CAPABILITIES AFFORDED THROUGH USE OF ELECTRONIC WORK PACKAGES}

With the advent of mobile technologies and supporting software capabilities, the nuclear industry is now poised to make drastic changes in the approach to work. In the past, the field worker (operator or maintenance staff) was required to carry work instructions in the form of paper that could be a simple single sheet of paper to very large three binders with hundreds of pagers. Operations and maintenance staff have used this paper-based system since the beginning of commercial nuclear power operations. Of most concern to the OCC staff are work packages. Work packages are the primary maintenance tool in the work management process. Over time, work packages have evolved into large binders of information that field workers are required to take into the field to execute work. Typically, work packages are organized into key informational sections such as a pre-job brief, purpose/scope, contingencies, work instructions, and additional supplementary information such as parts list, tool lists, schematics/drawings, and vendor technical manual information. Work packages are still used today in their original "static" hard-copy format and have become difficult to develop, implement, control, review, close out, archive, and manage. (EPRI 2013.)

The industry has responded to oversight organizations' audits and assessments that work package quality needs improved with volumes of more information that may or may not necessarily result in better quality and appears to have actually made the work packages more complex and less manageable. With the advent of an EWP, it is now possible to eliminate paper and create a human-systems interface (HSI) on a mobile device that is easy to use and will likely lead to significant maintenance and work management process improvements.

With all information needed to execute work on one simple-to-use device, the field worker can leverage the EWP with all available resources at his/her fingertips. EWP deployment in the industry has begun to occur; however, no research data are currently available to validate productivity or efficiency gains or the impact on human performance and specifically human error. It is however expected that key performance indicators from the NPPs that have deployed such systems will soon release the results of their adoption of EWPs in the very near future. INL's own research and vendor-related information indicates that it is very likely that positive results will be realized. EWPs performed within wireless coverage have potential to greatly improve communication and collaboration during both outages and online maintenance. INL's research into EWPs indicates that this new approach to field work will enhance human performance, efficiency, and safety by:

- Providing a means to consolidate all information related to field work in one central repository for ease of access and consistency in methodology

- Providing "information on demand" to key decision-makers who may need access to information related to field work progress 
- Increasing overall field work efficiency through rich data availability (e.g., sharing of digital photos, videos, voice, and messaging), and improved audio/visual communications

- Embedding operating experience in EWPs or CBPs in the form of rich data (videos and/or annotated photographs) to improve knowledge transfer as it relates to past events/issues

- Improving and/or enforcing procedural adherence (due to work progress monitoring by others)

- Improving safety by using the innate dynamic characteristics of EWPs and CBPs by providing context-based information and near-time work status information that can support decisions in the field

- Increasing communication and timely reporting of time-critical evolutions that lead to low-cost improvements in outage management that supports improved efficiency and reduced outage cost (i.e., allows related work or dependent work to ramp up more efficiently)

- Integrating requirements, support documents, and operator aids into the software leading to a reduction of the mental workload of field workers

- Providing instant notifications to update personnel on major milestones and state and status of the NPP

- Providing a dashboard view of all open and pending tasks for the field worker, makes it fast and simple to visualize all active work

- Allowing the supervisor to remotely assign work

- Allowing electronic reviews and approvals

- Providing remote communication and real-time collaboration (e.g., posted messages, voice messaging, audio, and text and chat)

- Providing video and voice reports to improve accuracy and information sharing

- Capturing rich data to provide electronic operating experience (EOE) for future use in briefings for EWPs and CBPs

- Providing NPP status information to display while the field worker is in the field performing the EWP and CBPs

- Improving collective situational awareness of the station

- Reducing administrative burden of printing, handling, updating, and scanning of work packages and procedures

- Providing electronic creation and assignment of new tasks

- Providing mobile application with off-line mode capability to allow continued work when WiFi connectivity does not exist or becomes unavailable.

The major challenge for outage staff is how to best leverage the increased volume of data and information that this new work management system can provide. The large amounts of data and information could easily overwhelm the OCC staff and actually hinder decision-making. The key will be how to best organize, display, monitor, track, and trend this information to enhance the functions of the outage staff to keep on schedule, make gains were possible, allocate resources, and most effectively address emergent issues as they arise. A significant effort to understand the available data and how best to display the data is essential for human factors engineers as they support the commercial nuclear industry in addressing the next generation of OCCs. 


\section{HUMAN FACTORS PRINCIPLES RELATED TO OVERVIEW DISPLAYS}

Human factors engineering (HFE) is an established science that uses multiple disciplines such as anatomy, psychology, cognitive engineering, systems engineering, and ergonomics to understand how people perform under different circumstances. A simple HFE definition is the study of all the factors that make it easier to do the work in the right way. Another definition of human factors is the study of the interrelationship between humans, the tools and equipment they use in the workplace, and the environment in which they work (Kohn et al. 1999).

The INL AOCC Project team recommends applying formal HFE methodologies and principle to the design of next generation OCCs. This approach will provide an OCC design that is centered on eliminating ergonomic issues, incorporating technology tools to assist the outage staff, and optimizing outage staffing. The various functions that the OCC must perform will be retained, but the methods to accomplish these functions (function allocation [FA]) may change dramatically by using technology and function reallocation. The number of permanent staff physically located in the OCC should also be considered when re-engineered; this is a methodical approach to determining who should be in the OCC and what they should be doing based on the increased use of communication and collaboration hardware and software technology to effectively execute an outage.

Decision-making will likely be approached in new and profound ways that past practices, limited automation, and antiquated tools could not achieve. Computer automation and new hardware and software will enable capabilities that were once provided by the brute force of a literal army of people to be achieved with little or no effort allowing for better use of resources (staff) to achieve greater efficiencies. The ability to remotely send and receive information from the field, work stations, and/or a geographically-dispersed work force of experts is already reshaping other industries such as the military in new ways not possible just a decade ago. The commercial nuclear industry is in the process of trying to capitalize on such innovation with the help of INL research staff that is showing the industry the possibilities through concept demonstrations and actual deployment such as the use of collaboration software to address outage emergent issues.

\subsection{Information Comprehension}

Poor decision-making or performance is often blamed on the individuals; however, when the event is investigated further, the conclusion often points to something beyond the person who erred. Good HFE can typically help improve future decision-making by addressing the task, task demands, display (HSI), and training needed for success.

The use of task analysis and work domain analysis will reveal the actions required (task demands) and how humans use information available to them to make the necessary decisions. Using HFE tools and methods will typically lead to redesign of the task itself and HSI. Decision aides or decision-support systems help the performer execute the task successfully. These aides or systems come in many forms from simple flow diagrams to complex interfaces on computer screens. Much has been learned about how to maximize the usefulness of these types of systems, including recognizing that data are not information and that data alone will not improve performance. Information needs to be in a form that is easily discernable and should be designed to improve the cognitive decision-making abilities. (Wickens et al. 2004, p. 177.) 
Given that data alone or data with simple graphics alone are not information, the question arises as to what makes a good display. With the use of many types of sensors or data from enormous databases, there is the possibility of huge amounts of data available to the performer. It is not uncommon to see in large command and control centers computer screens with thousands of pieces of data that can be scrolled through or large screen displays with data appearing next to a graphical representation of a component, a complex system, or multiple systems that are interconnected. However, this can be very overwhelming to the performer or have little to no meaning given the context of the moment. There must be a better way to provide decision support systems beyond excessive discrete data displays.

How these data are displayed will play a key role in its usefulness to the performer when making critical decisions. Compressing the large amount of data into useable information requires a tremendous amount of effort; however, it should yield much improved results. Human factors engineers and system engineers face one challenge of how to compress the vast amount of information and make it simple to use and easy to comprehend when large amounts of data are available. One approach is to determine what level of granularity of the data is needed and in what form the data should be displayed. Several questions need asked to make these determinations:

- Is there a need to see discrete data all the time?

- Is the discrete information alone valuable to the performer to accurately make the correct decision?

- Can the data be displayed using a trending graphically display? Is this more a useful form?

- Can the discrete data be displayed using color coding to provide additional information about the state or status of the process or system?

- Will a digital or analog display or combination of the two improve understanding by the performer?

- What critical decisions are required by the performer?

Another consideration relates to Question 5, analog versus digital. Quite often we mistakenly believe that digital being newer is always better; however, this is not always true. A prime example of this is to think about digital and analog watches. When digital watches first came onto the market they were highly sought after, today you will find few people who wear one, why is that? The simple answer is that people are not typically concerned about the actual time but rather how much time they have left or time to get to the next appointment. The analog watch makes that much simpler to determine at a glance. The wearer of the watch can quickly see that it is 18 minutes until 12:00 pm and know that he/she has 18 minutes until lunch. Now take a digital watch, the wearer must look at the digital display and calculate that 11:42 am means that he/she has 18 minutes before lunch. Use of a digital watch requires more mental resources and time for the wearer to determine how long he/she has until lunch. (Hollifield et al. 2008.) This same principle can be applied to HSI displays that try to aggregate large amounts of information into one display. Clearly more data do not equate to better information or better decision-making. The understanding of these principles should help HFE in the approach to providing dynamic HSIs that improve outage management.

\subsection{Physical Display Characteristics}

Information compression as mentioned above will require very accurate task analysis to determine what and how to display information to maximize cognitive decision-making. To provide the best physical display, several factors need to be considered prior to finalizing the interface. Consideration must be given to the following questions:

- What size of the display (monitor size) is needed?

- Will multiple monitors be used?

- Will some displays provide a scrolling display for multiple parameters or information? 
- Will the use of color add value to the information or make it more confusing?

- What colors will be used?

- If colors are to be used, what will they represent?

- Will trending graphics improve the performer's understanding?

- If a trending display is used (where you were and where you are), can the system also predict and display where you will be based on the current trend? Should it?

- Should a "drill down" function be provided to allow the performer the ability to see discrete data?

- How or should related data be displayed such as the time remaining or required, percent complete, and work order number?

- Should the display be static, dynamic, and/or have animation?

- How much configuration of the information should be in the individual's hands (i.e., performer can change what is displayed and how it displayed)?

- What shapes will be used to represent different types of information?

- Should additional information be provided by hovering over an item on the display?

- Should multiple users be able to interact with the display from different locations or only one location?

- If multiple users use the same information, should they have the ability to display it differently on their local display or should a master configuration be displayed to all other users?

- If video feed(s) is provided, can it be paired with other display functions (e.g., video from the worksite displayed next to the CBP or AWP)?

- How should sound be use to inform the performer (e.g., alarms or warnings)? No sound?

- How will haptic feedback (tactile feedback technology) be used to provide the performer a sense of touch when manipulating the system interface? Is it needed?

- Should electronic (digital) pens that convert analog handwriting or markings into digital data be used? If used, what functions are needed (e.g., touch sensitivity, input buttons, memory, variety of marker types, and electronic eraser)?

- What type of training will be required if training is required?

To assist HFE in evaluating the appropriate allocation of functions for the human and software and what are to be shared functions, a FA analysis is used. The FA analysis allows HFE to evaluate the current allocation of functions required to successfully execute work using the current process and new systems after deployment of new technologies, processes, and/or systems. According to ISO (1999), the allocation of function is "the division of system tasks into those performed by humans and those performed by technology.' As new technology is deployed, human-performed tasks may be allocated to software and automated. With FA analysis, HFE can ensure that all the tasks previously identified are properly allocated to human, automation, or shared. The FA analysis helps to determine that the optimal division of activities and labor to maximize the innate capabilities of both the human and machine. 
Figure 1 shows the output of a possible FA analysis for an OCC display, illustrating how to visualize the output of FA analysis to show the current process. In this scenario, the outage manager and outage support staff review and evaluate the current scheduled work, required resources, and actual resources available to execute work for the specific functional area. The outage support staff calls and requests supervisors to evaluate resource allocation for the scheduled work to determine how to modify current deployment of staff and provides input to the outage manager. Based on input from the outage support staff, the outage manager determines how best to accomplish critical path items that are scheduled. The OCC staff develops and sends a new plan for work to the scheduler to modify the scheduling software. The scheduler receives the new plan for work and modifies the scheduling software to reflect the changes. The scheduler prints and sends a new schedule to the OCC staff to replace the previous version. The outage manager and OCC staff evaluate the new schedule and give new work direction to supporting organizations.

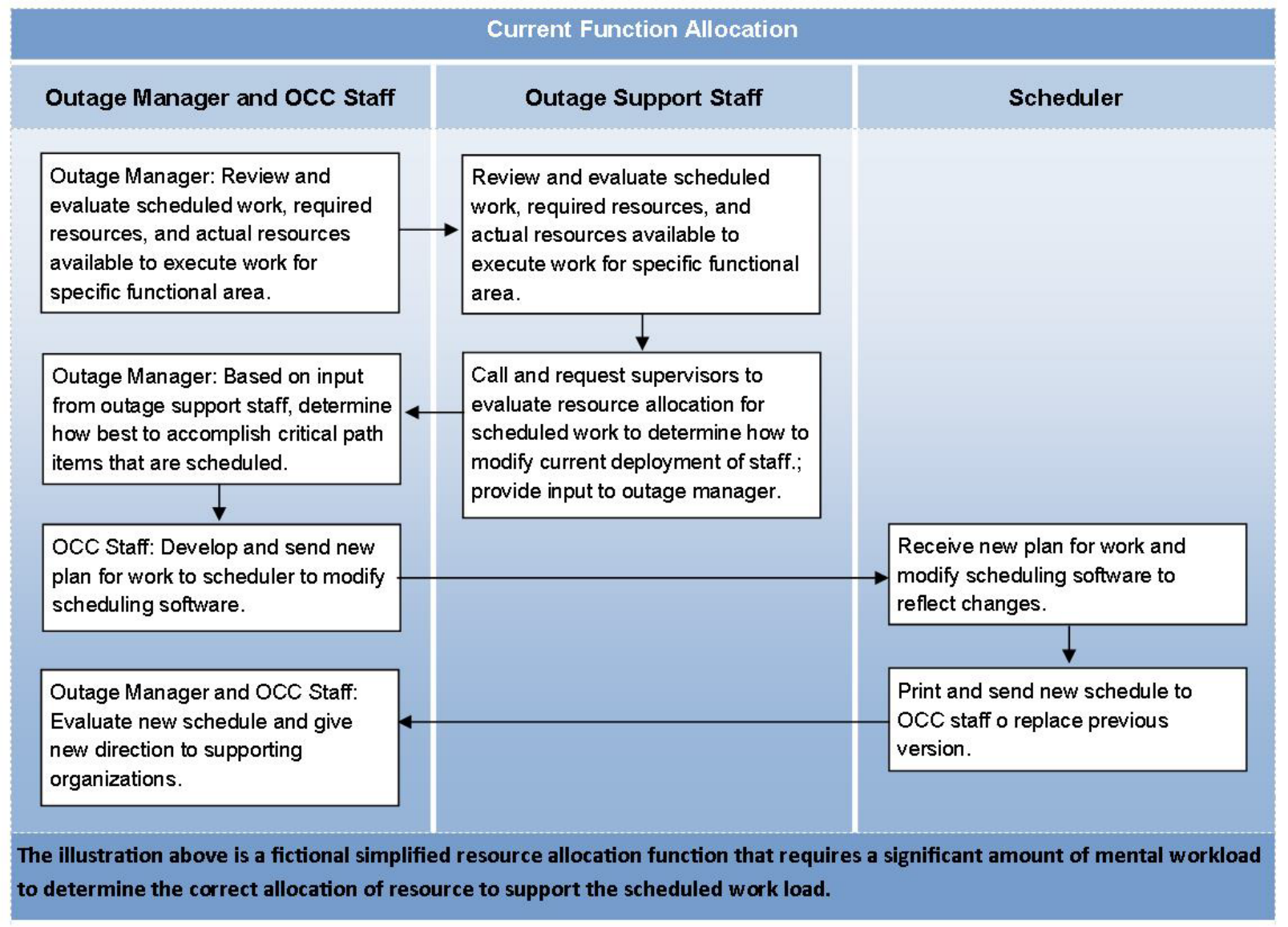

Figure 1. Function allocation analysis table, "current" function allocation illustration.

Figure 2 shows the output of a possible FA function analysis for an OCC display, illustrating how to visualize the output of FA analysis to show the desired process. In this scenario, the outage manager is viewing the newly-developed resource allocation display in the OCC and sees a "yellow" warning of an impending resource availability conflict to execute work. The outage manager and outage support staff evaluate the display and move visual representation tools (icons or other symbols that represent the information) to reshuffle work to create a more efficient use of resources. The Resource Allocation Software (RAS) tool automatically recalculates various scenarios put forth by the outage manager and OCC support staff. The outage manager accepts the new schedule that was created by pushing ACCEPT on the HSI (the display). The RAS receives the request to change the schedule from the outage manager 
and notifies the scheduler to modify the scheduling software to reflect the changes. The scheduler receives the new plan for work from the RAS and modifies the scheduling software to reflect the changes. The new electronic P6 schedule becomes available to all users, including the outage manager and OCC staff. The outage manager and OCC staff view the new schedule and get confirmation from the various organizations' supervisors of their acceptance to give new work direction.

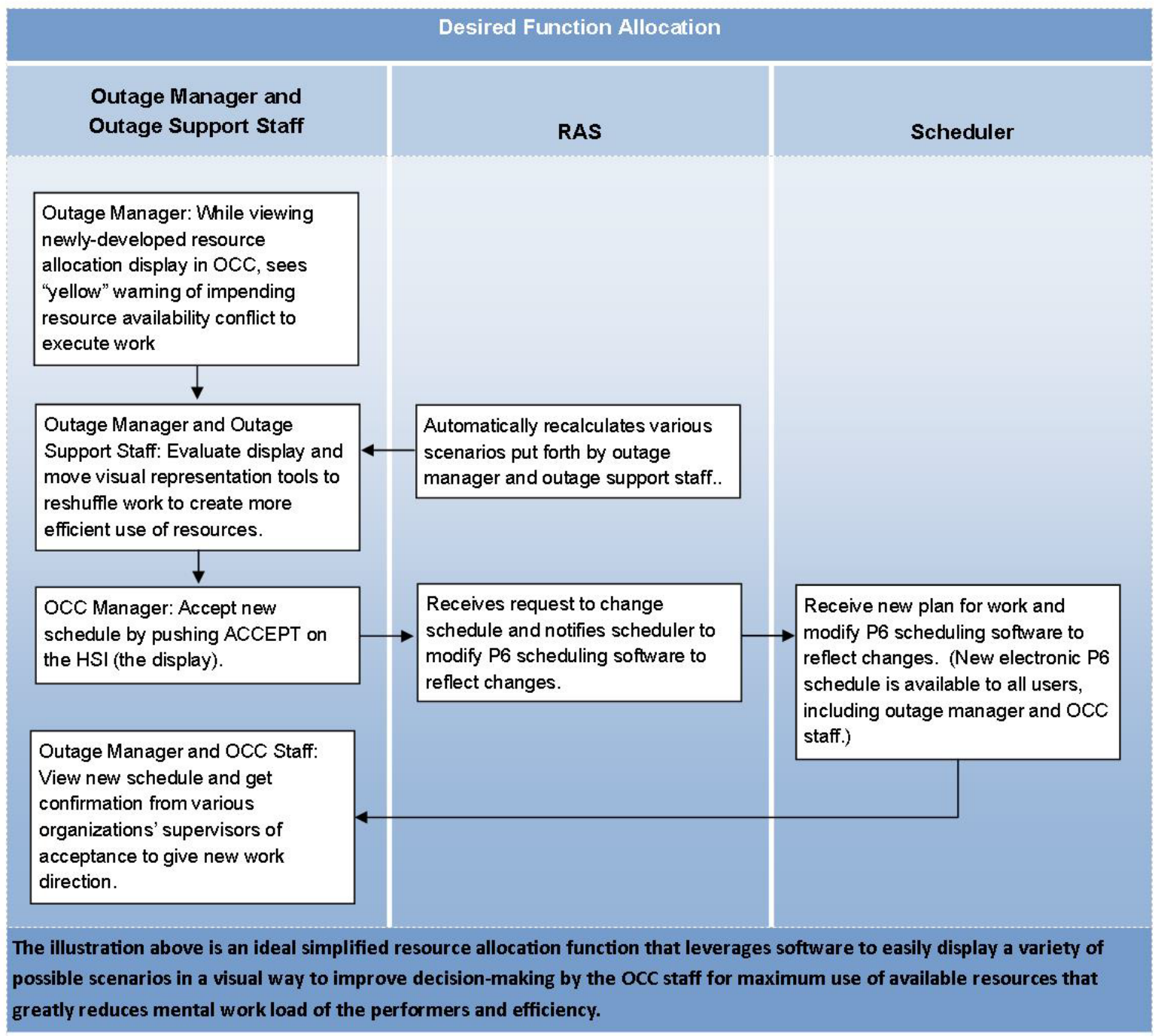

Figure 2. Function allocation analysis table, "desired" function allocation illustration.

Although, the current and desired FAs were fictional, these two FA analysis tables in Figure 1 and Figure 2 visually show the contrast between the "as is" (current) and "to be" (desired) for these functions. In the "current" fictional process, there is a significant amount of manual work and mental workload required to execute this function. In the "desired" (to be) process, it should be obvious that functions that once were manual are now automated. The efficiency gains that can be realized by such a system will vary and will be driven by the complexity of the function, user experience level, network speed, and other performance shaping factors. 


\section{RECOMMENDATIONS FOR OVERVIEW DISPLAYS}

Visual displays are an important part of maintaining staff alignment, both for staff assigned to the OCC and staff that visit the OCC to interface with the assigned staff. The type and quantity of information displayed in the OCC will depend on the number and makeup of staff assigned to the OCC, physical dimensions of the OCC, desk configuration, and physical availability to place displays in the OCC (especially wall space in the OCC). The use of electronic displays allows much more information to be displayed in a smaller area; the information displayed is configurable and modern display panels are easily viewed at sharp angles. Electronic displays may also be manually toggled easily to switch information being displayed as needed or automatically roll through a predefined list of displays showing one at a time for a predefined period.

\subsection{General Recommendations for Electronic Displays}

Displays can be characterized in human factors terms as human-made artifacts designed to support perception of relevant system variables and facilitate further processing of that information. Before a display is designed, the task that the display is intended to support must be defined (e.g., navigating, controlling, decision-making, learning, and entertaining). A user or operator must be able to process whatever information that a system generates and displays; therefore, information must be displayed according to principles in a manner that will support perception, situation awareness, and understanding.

Wickens et al. (2004) defined 13 principles of display design. These principles of human perception and information processing can be used to create an effective display design. A reduction in errors, a reduction in required training time, an increase in efficiency, and an increase in user satisfaction are a few of the many potential benefits that can be achieved through use of these principles. Certain principles may not be applicable to different displays or situations. Some principles may seem to be conflicting, and there is no simple solution to say that one principle is more important than another. The principles may be tailored to a specific design or situation. Striking a functional balance among the principles is critical for an effective design. The Wickens et al. (2004) 13 principles of display design include the following:

\section{- Perceptual Principles}

1. Make displays legible (or audible). A display's legibility is critical and necessary to design a usable display. If the characters or objects displayed are not discernible, then the operator cannot effectively make use of them.

2. Avoid absolute judgment limits. Do not ask the user to determine the level of a variable on the basis of a single sensory variable (e.g., color, size, and loudness). These sensory variables can contain many possible levels.

3. Top-down processing. Signals are likely perceived and interpreted in accordance with what is expected based on a user's experience. If a signal is presented contrary to the user's expectation, more physical evidence of that signal may need to be presented to assure that it is understood correctly.

4. Redundancy gain. If a signal is presented more than once, it is more likely that it will be understood correctly. This can be done by presenting the signal in alternative physical forms (e.g., color and shape and voice and print), as redundancy does not imply repetition. A traffic light is a good example of redundancy, as color and position are redundant.

5. Similarity causes confusion: Use discriminable elements. Signals that appear to be similar will likely be confused. The ratio of similar features to different features causes signals to be similar. For example, A423B9 is more similar to A423B8 than 92 is to 93 . Unnecessary similar features should be removed and dissimilar features should be highlighted. 


\section{- Mental Model Principles}

1. Principle of pictorial realism. A display should look like the variable that it represents (e.g., high temperature on a thermometer shown as a higher vertical level). If there are multiple elements, they can be configured in a manner that looks like it would in the represented environment.

2. Principle of the moving part. Moving elements should move in a pattern and direction compatible with the user's mental model of how it actually moves in the system. For example, the moving element on an altimeter should move upward with increasing altitude.

\section{- Principles Based on Attention}

1. Minimizing information access cost. When the user's attention is diverted from one location to another to access necessary information, there is an associated cost in time or effort. A display design should minimize this cost by allowing frequently accessed sources to be located at the nearest possible position. However, adequate legibility should not be sacrificed to reduce this cost.

2. Proximity compatibility principle. Divided attention between two information sources may be necessary to complete one task. These sources must be mentally integrated and are defined to have close mental proximity. Information access costs should be low, which can be achieved in many ways (e.g., proximity, linkage by common colors, patterns, and shapes). However, close display proximity can be harmful by causing too much clutter.

3. Principle of multiple resources. A user can more easily process information across different resources. For example, visual and auditory information can be presented simultaneously rather than presenting all visual or all auditory information.

\section{- Memory Principles}

1. Replace memory with visual information: knowledge in the world. A user should not need to retain important information solely in working memory or retrieve it from long-term memory. A menu, checklist, or another display can aid the user by easing the use of his/her memory. However, the use of memory may sometimes benefit the user by eliminating the need to reference some type of knowledge in the world (e.g., an expert computer operator would rather use direct commands from memory than refer to a manual). The use of knowledge in a user's head and knowledge in the world must be balanced for an effective design.

2. Principle of predictive aiding. Proactive actions are usually more effective than reactive actions. A display should attempt to eliminate resource-demanding cognitive tasks and replace them with simpler perceptual tasks to reduce the use of the user's mental resources. This will allow the user to not only focus on current conditions, but also think about possible future conditions. An example of a predictive aid is a road sign displaying the distance to a certain destination.

3. Principle of consistency. Old habits from other displays will easily transfer to support processing of new displays if they are designed consistently. A user's long-term memory will trigger actions that are expected to be appropriate. A design must accept this fact and use consistency among different displays. 


\subsection{Information Displays}

An outage encompasses different phases of activities, they are dynamic by nature, and as a result, they create challenges to the display configuration required to support the activities in the most effective way. The type of information displayed in the OCC will change as the outage progresses. Early in the outage, chemistry and cooldown information may be desired. During the refueling window, a graphic of the core showing fuel bundles may be the focus. Coming out of the outage, Mode 4 requirements may be displayed. Use of electronic displays makes it easy to change the content and arrangement of information being displayed. Today, some of the more common displays found in an OCC are as follows:

- Schedule monitor

- Overview display for work completion metrics

- Station priorities list

- Emergent issues list

- Outage safety display (e.g., risk level, protected equipment, and time-to-boil)

- Maintenance issues

- Engineering issues

- Materials issues

- Containment cameras

- Refuel floor cameras

- Emergent issues cameras

- Refueling map display

- Real-time collaboration display.

Some displays may be permanent throughout the outage, while others cycle or are shown on demand and/or are needed only for a finite period during certain phases of the outage.

One of the challenges HFE faces is to design a system that addresses the dynamic nature of the displays needed as the outage progresses. It is important to remember that the proactive presentations of information are usually more effective than reactive actions especially as the OCC is trying to predict and plan. The outage staff will have various cognitive tasks that will create varying demands on individuals and the team assigned to the OCC. OCC displays should attempt to simplify information and reduce the user's mental workload if at all possible. The results from such displays will enable much improved prognostic and diagnostic capabilities, (i.e., focus on current conditions, but also think about possible future conditions, and understand any upsets or issues that arise).

An example of a prognostic OCC aid is a graphical display of available resources (various outage staff) to support performance of a complex maintenance work package. The display could automatically analyze the work activities scheduled, resources required, and resources available and display the results such as the need for two additional mechanics should the work start at 2 p.m. This type of display would require very little cognitive skills and allow the OCC staff the necessary tools to shift scheduled work around to show how reallocation of resources could support the planned work without actually touching the schedule, rather manipulate an ideal schedule. This type of tool would anticipate the need of a performer, predict the conflict, and provide information to the decision-makers without a request for such information to allow for better decision-making. 
A diagnostic OCC aide might include any number of available information resources about an emergent issue such as live video from the field, drawings/schematics, construction photos of the component, emergent issue package from another NPP for the same or similar issue (operating experience), and any number of relevant sources of information to support issue response. This diagnostic display might require mashing of multiple sources of information into one or several displays, live feeds from the field, task list monitoring, resource allocated and current location, etc. to maximize the collective situational awareness of the team and those monitoring the progress. This can be a challenge for the designer of such a system as this is no finite set of information that can and will be displayed given the complexity of NPPs and varying context under which such issues can arise.

\subsection{Dynamic Schedule Monitor Display}

Leveraging the stream of real-time information that will be available through the use of EWPs described in Section 3 will allow the use of a more robust and intelligent schedule monitoring tool. Conceptually, the dynamic schedule monitor will be able to display a view of the schedule similar to what the OCC staff is currently manually updating to keep track of status. The dynamic schedule monitor will update the status of ongoing work automatically by monitoring the status of ongoing work being performed via EWPs connected with WiFi to the NPP system. The dynamic schedule monitor will be able to project the impact of schedule deviations on subsequent schedule activities. The system will also allow the field worker to update the estimated completion time through the EWP and the supervisor will be notified that a potential schedule deviation (or conflict) exists and can decide the most effectively way to adjust the schedule. If a field worker reports that an activity may finish early, the supervisor will be alerted of an early finish; however, the software tool will not automatically adjust subsequent activities. This lack of automatic action is deliberate because it is anticipated that the supervisor may have reasons to keep future tasks as originally scheduled. This function is based on the principle that the performer, the supervisor, understands the complexity of the process(es) and context of the given situation better than a software system. This system will however, enable the supervisor the option to pull ahead work due to early completion or not. Similarly, the system will automatically update schedule activities with the actual completion time/date; however, the lack of completion will not automatically adjust the schedule. The supervisor can also receive a visual cue from the system when an activity has not completed as scheduled, but the system will not automatically adjust subsequent tasks or subtasks associated with the primary task. This function is driven by the idea that it is possible that the lack of completion may not be real (work is actually complete). For example, the worker may be out of WiFi coverage or the worker or supervisor may have simply forgotten to electronically sign off the completed activity. In this case, the supervisor could see the visual cue and investigate the actual status of the work. If the schedule delay is real, the supervisor could enter an updated estimated completion time and all the tied subsequent activities or subtasks would be automatically adjusted to reflect the change. Supervisors responsible for these subsequent tasks and subtasks could see the schedule deviation and adjust their work plans and resources accordingly.

The dynamic schedule monitoring software tool would conceptually be able pull the scheduled activities and logic ties from the NPP's existing scheduling software. The system may or may not be configured to update the NPP's schedule software depending on preference. Each day, after the official schedule has been reconciled, the software tool would pull down the scheduled activities for the day or shift creating a visual display and the process would start again.

The expected benefits of the dynamic schedule monitor include improved coordination of handoffs, improved allocation of resources by shop supervisors, less time spent by OCC decision-makers chasing work status, and automatic collection of key performance data. 
The dynamic schedule monitoring software tool will use a Gantt chart type display similar to the output of most scheduling software tools used in commercial NPPs. This system will be designed such that a system of color coding and shading will alert the supervisors to any schedule deviations that might arise. The visual conventions shown in Figure 3, Figure 4, and Figure 5 were developed with input from INL research staff, a software vendor, and commercial nuclear staff and will be used for the initial prototype; they will be adjusted after additional field trials are performed.

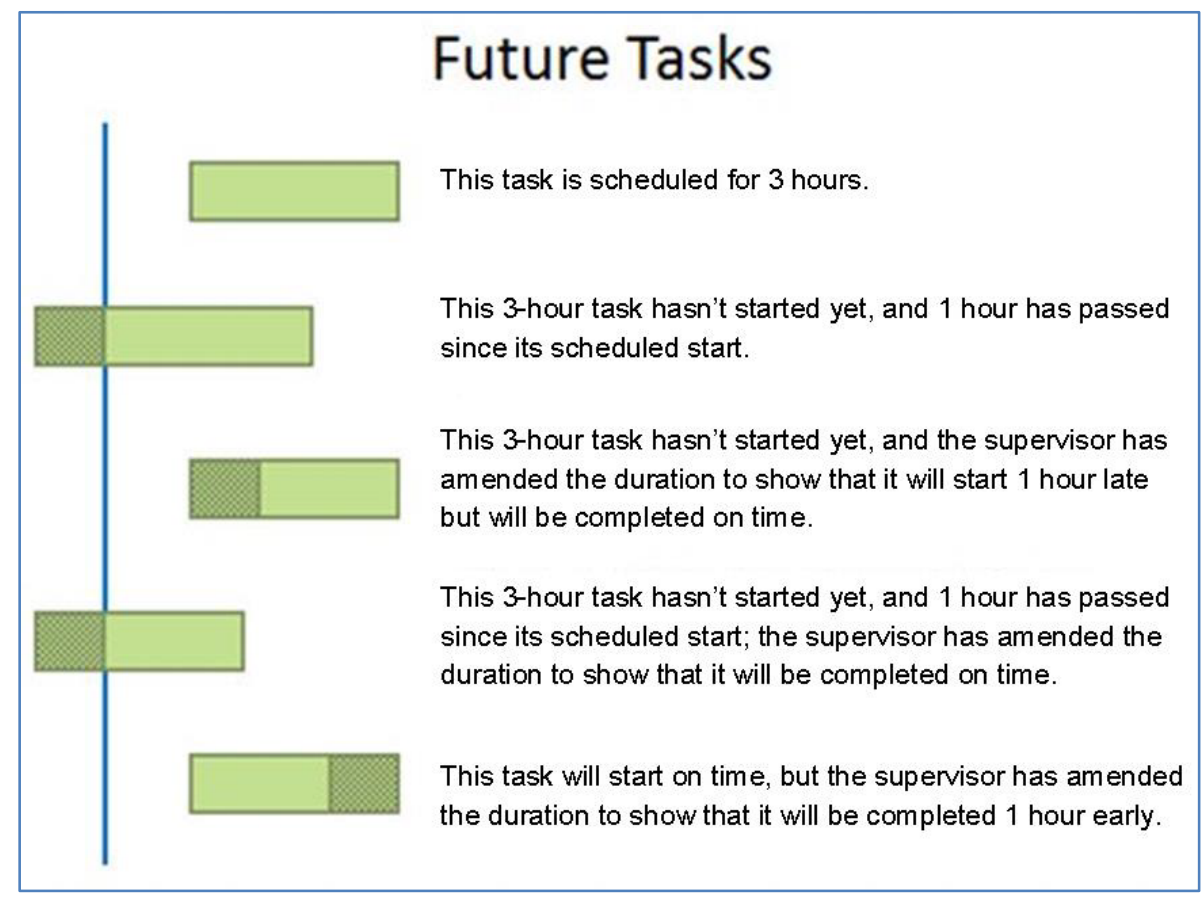

Figure 3. Display concept for tasks not started.

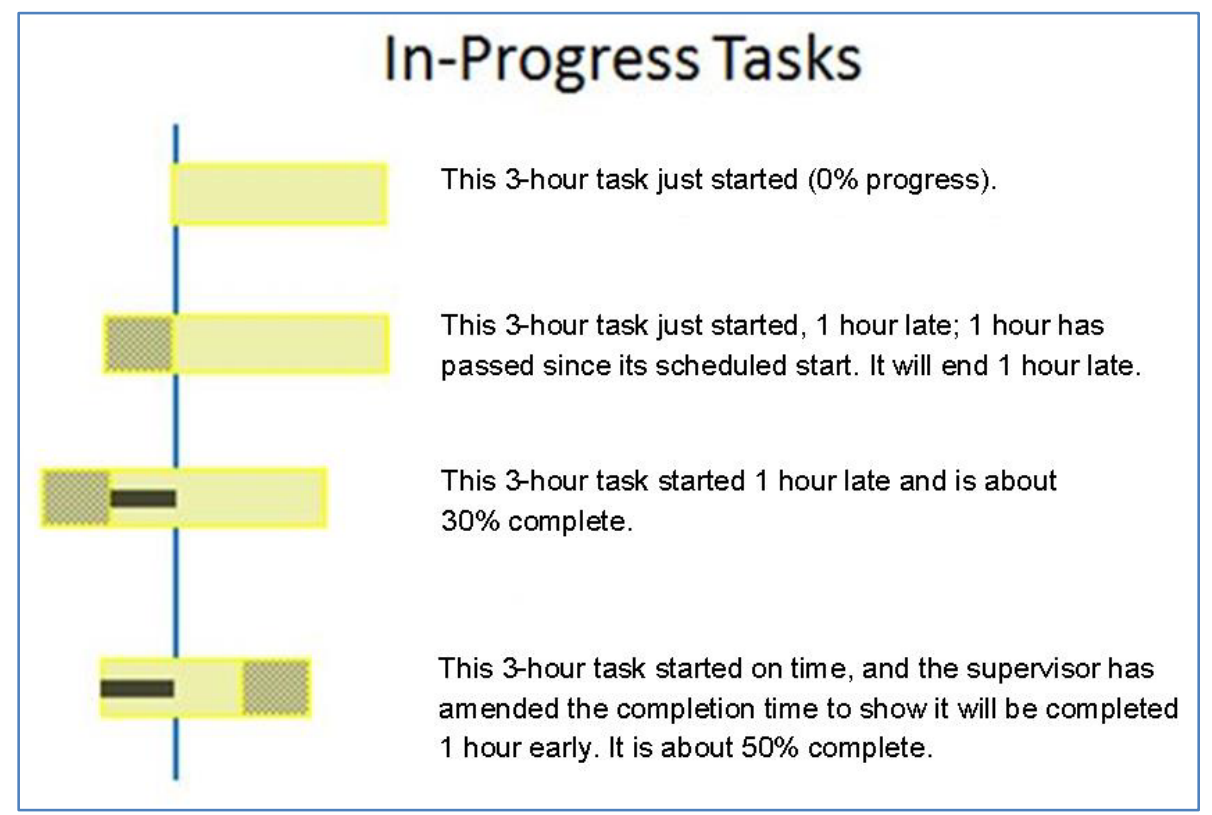

Figure 4. Display concept for tasks in progress. 


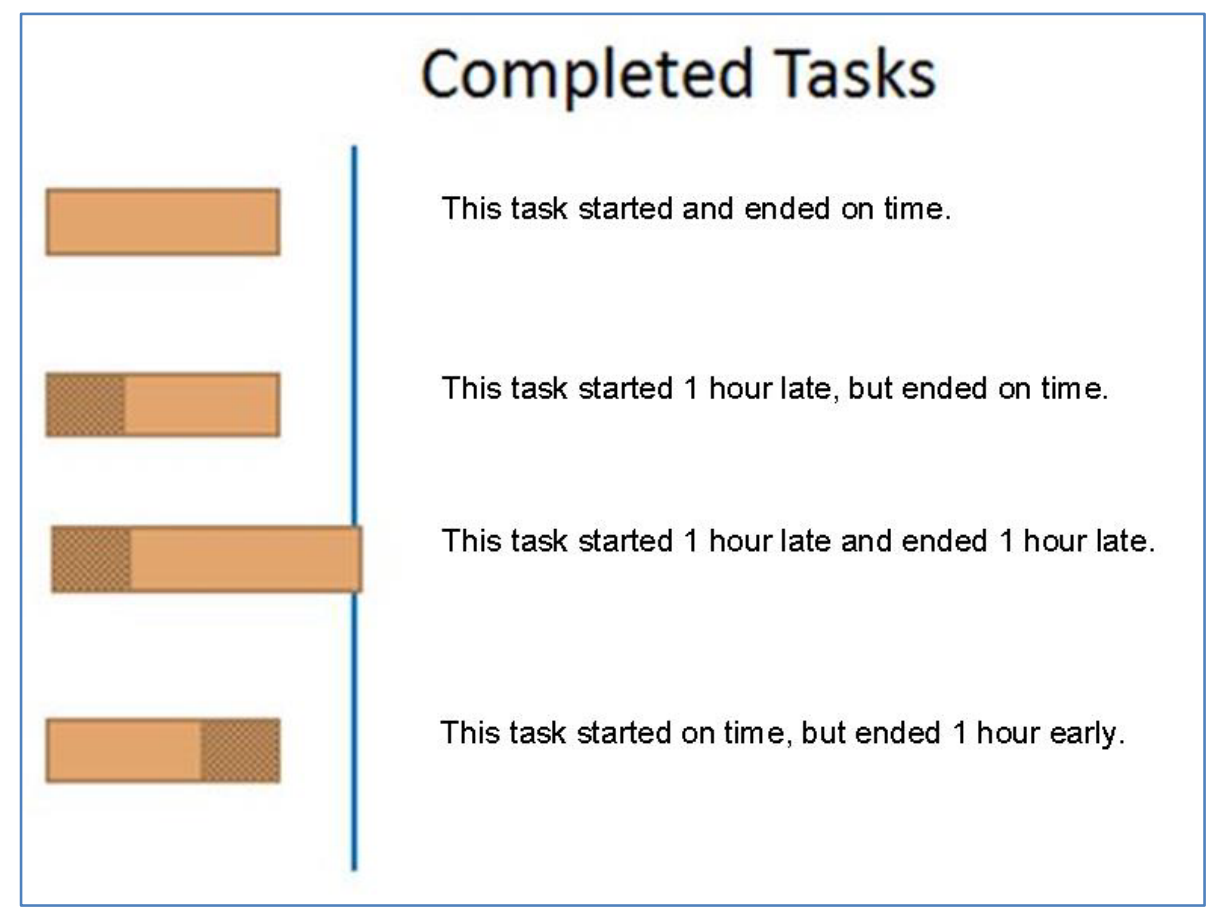

Figure 5. Display concept for completed tasks.

The initial demonstration of a functional dynamic schedule monitor is shown in Figure 6, Figure 7, and Figure 8. INL worked with Curtiss-Wright to develop the dynamic schedule monitor as an application within Curtiss-Wright's existing EWP software application. This initial schedule monitor tool was designed and developed to assist the OCC staff in monitoring and controlling "critical path" and "near critical path" work. Successful execution of the outage requires excellent communication, control, and "handoffs" for critical path work. To effectively accomplish effective "handoffs," the entire organization needs to understand the status of ongoing work and expected completion time for the current critical path activity or activities. This coordination of work is typically managed through an intensively manual process requiring a significant amount of mental workload to follow each work activity and to rely on workers and supervisors to update outage staff that typically manually updates a printout or list of scheduled activities for the day. A live demonstration of the dynamic schedule monitor was conducted at Palo Verde Nuclear Generating Station during the station's Spring 2015 refueling outage. The demonstration included converting one of the station's actual work packages into a EWP. The EWP was performed on an I-Pad tablet connected to a wireless network (Figure 6). A supervisor's display allowed the status of the work package to be tracked in real time (Figure 7). An OCC overview display was also automatically updated by the system as work was completed using the EWP in the field (Figure 8). 


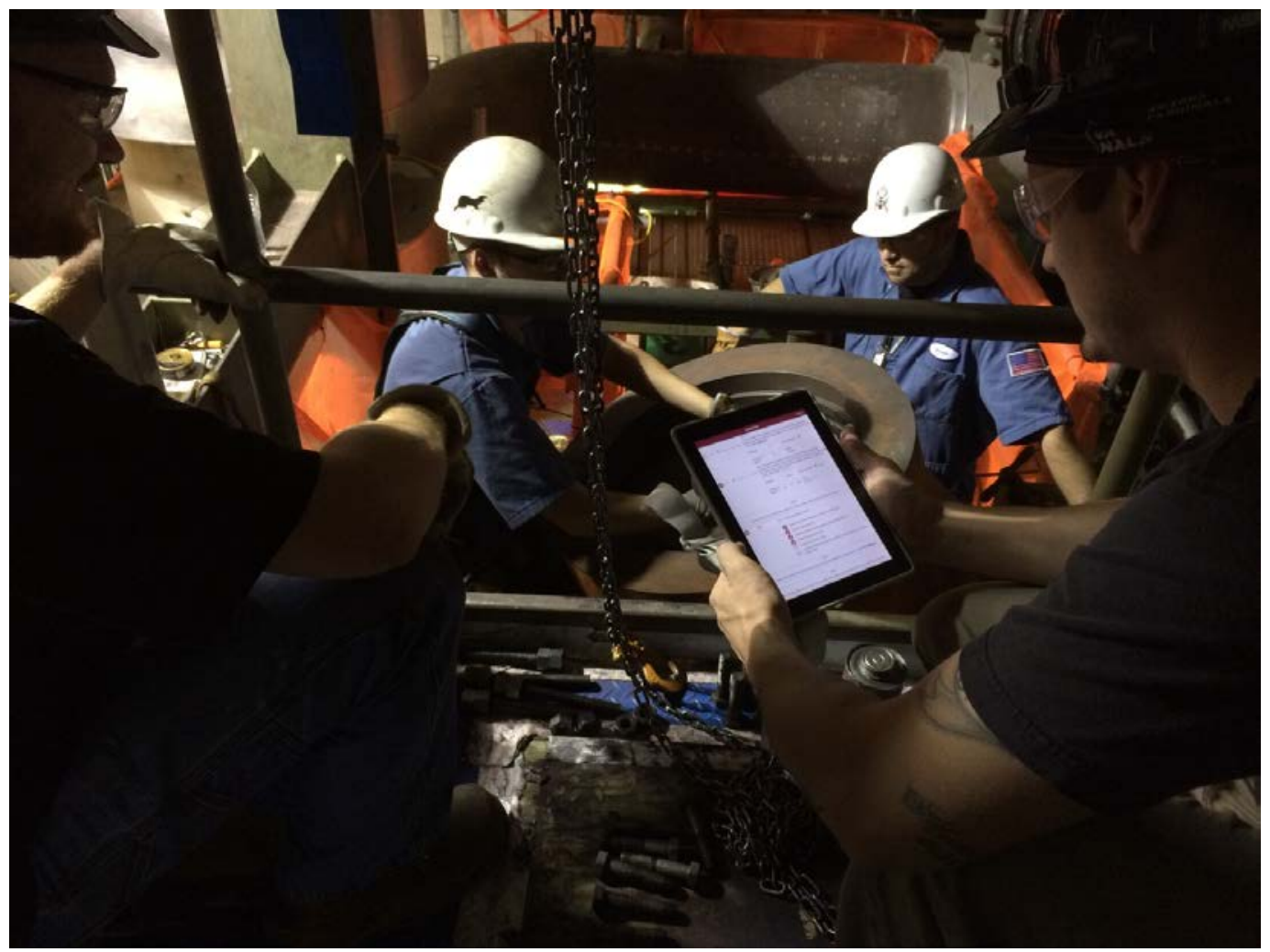

Figure 6. Field workers using electronic work package at Palo Verde.

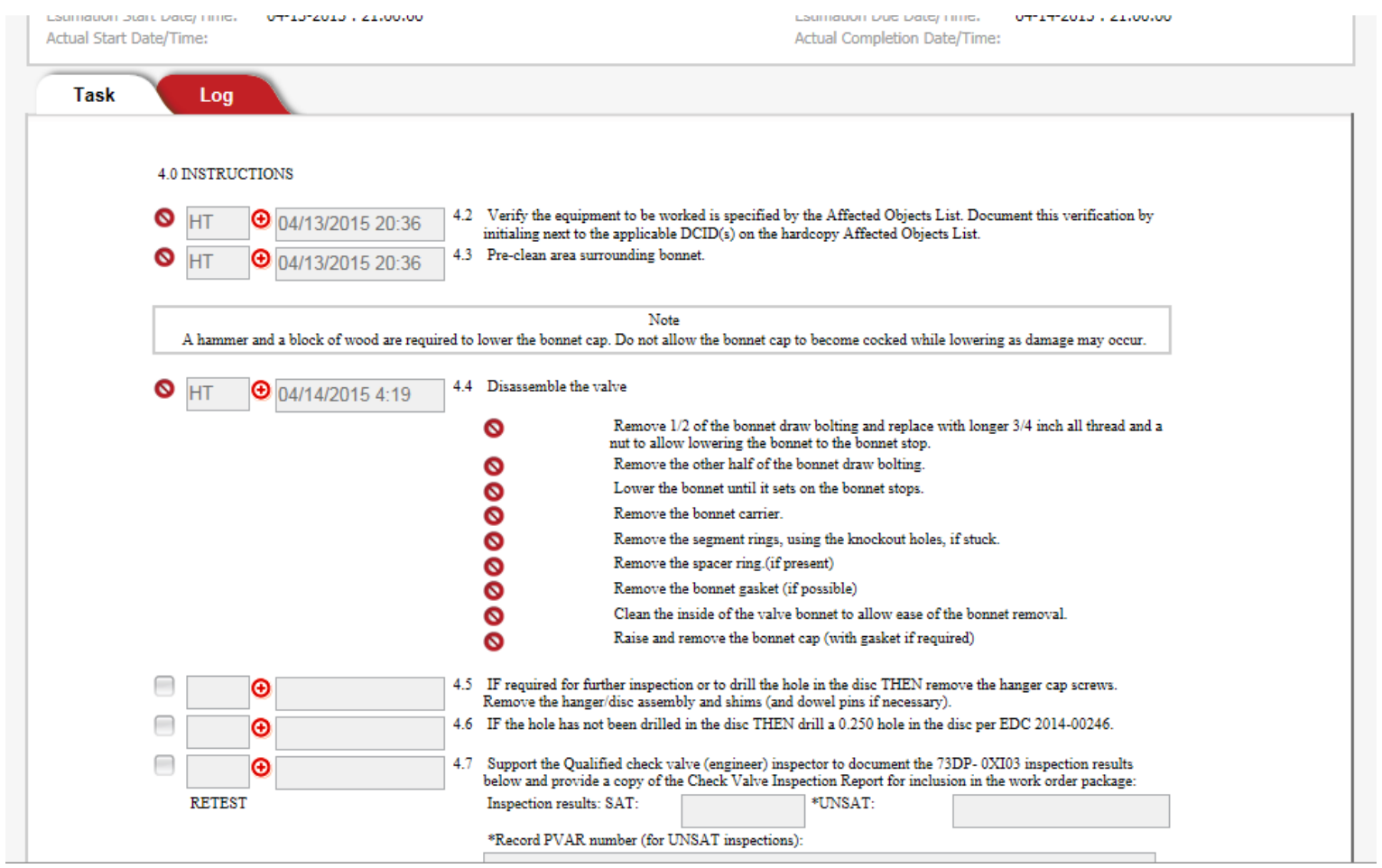

Figure 7. Sample of supervisor's work monitoring display. 


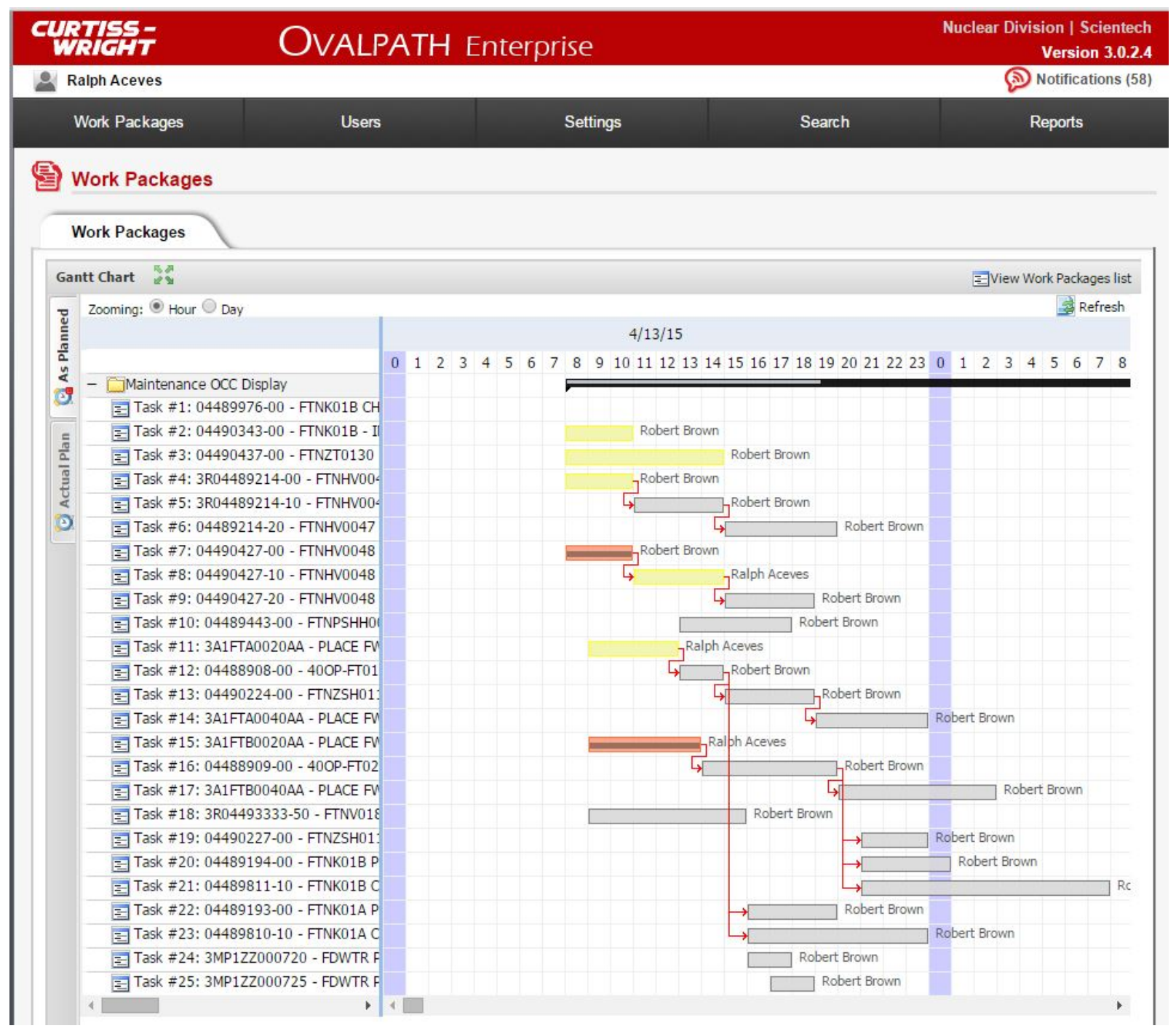

Figure 8. Dynamic schedule monitor demonstration.

Feedback from the demonstration participants was very positive. The supervisors appreciated the ability to easily monitor work status remotely. The field workers felt the EWP worked well, they particular liked the ability to have all the reference materials available in the field. The automatic status updates to the OCC display worked as designed. Field workers and supervisors recommended several enhancements that will be incorporated into an improved design for demonstration during Palo Verde's upcoming Fall 2015 refueling outage.

Some participant comments received in the demonstration include the following:

- A Palo Verde mechanical team member said: "Taking part in the pilot group and testing the first implementation of an electronic work order was a great opportunity to help site maintenance step into the future. The system is very user friendly and has endless applications. With the feedback provided by myself and my co-workers, electronic work orders will increase the efficiency of turnovers and status updates by providing real time information directly from the field, as well as ease the administrative burden of the frontline." 
- A Palo Verde team leader said: "For a supervisor or coordinator, you are able to see live status from the device in the field at your computer as the crew performs each circle, slash and verbiage typed in comment sections. It also tracks WO packages similar to Syntempo. This would eliminate a lot of inaccurate status in our schedules and help the supervisors plan jobs for the day or further out in the future. It would be amazing as a frontline worker to have all procedures, drawings and documents in their hands to make jobs that more efficient. I was very impressed with the product that was provided so far and am hopeful the feedback we provided will help bring this into our daily lives."

- A Palo Verde maintenance director said: "This is an example of improving our tools for our craftsmen. Improved tools whether documents, vendor manuals or electronic tools like this pilot, help our craftsmen and their ability to interface with the plant and do their work in the field. By having the information needed in an electronic work order package, they can eliminate distractions, avoid delays and work efficiently to do what they do best - providing quality craftsmanship work in the field."

In the future, additional capabilities will be built into the system to provide supervisors with a plot of resource requirements hour by hour throughout the day based on information the dynamic schedule monitor provides.

\subsection{Overview Display for Work Completion Metrics}

The tracking of bulk work creates unique challenges for the OCC staff. As stated earlier, the schedule creep is the most challenging aspect of monitoring thousands of maintenance items. The OCC staff currently monitors bulk work with "burn-down curves." Outage delays in completing bulk work and the resultant bow wave created by various delays can overwhelm the task support resources needed near the end of the work window. The challenge then becomes not letting bulk work impact the critical path. Research indicates that an overview display for work completion metrics will likely be the most effective method to monitor completion of bulk work. The use of the dynamic schedule monitoring software tool described in the previous section should improve the productivity of the organization, but to truly understand the capability of the organization to complete the volume of bulk work with the time constraints of the critical path work, a more robust means of monitoring of work completion is required. The typical metrics used to monitor work as described in Section $\square$ are activities and man-hours. Commercial NPPs employ many strategies today to try and monitor performance through various combinations of these metrics. Outage managers today typically look at progress-to-date in relation to the schedule and progress made in the previous 24 hours. Figure 9 shows an example of a utility dashboard to monitor bulk work completion. Based on results shared by many outage managers, there still remains much room to improve with respect to bulk work monitoring. Based on this feedback, additional research will be made into how big data analytics may be applied to the various sources of information related to work completion to determine what would be the best leading indicator of schedule compliance and assurance that bulk work will be completed on time. Research into application of big data analytics to bulk work monitoring will occur during Fiscal Year 2016. 


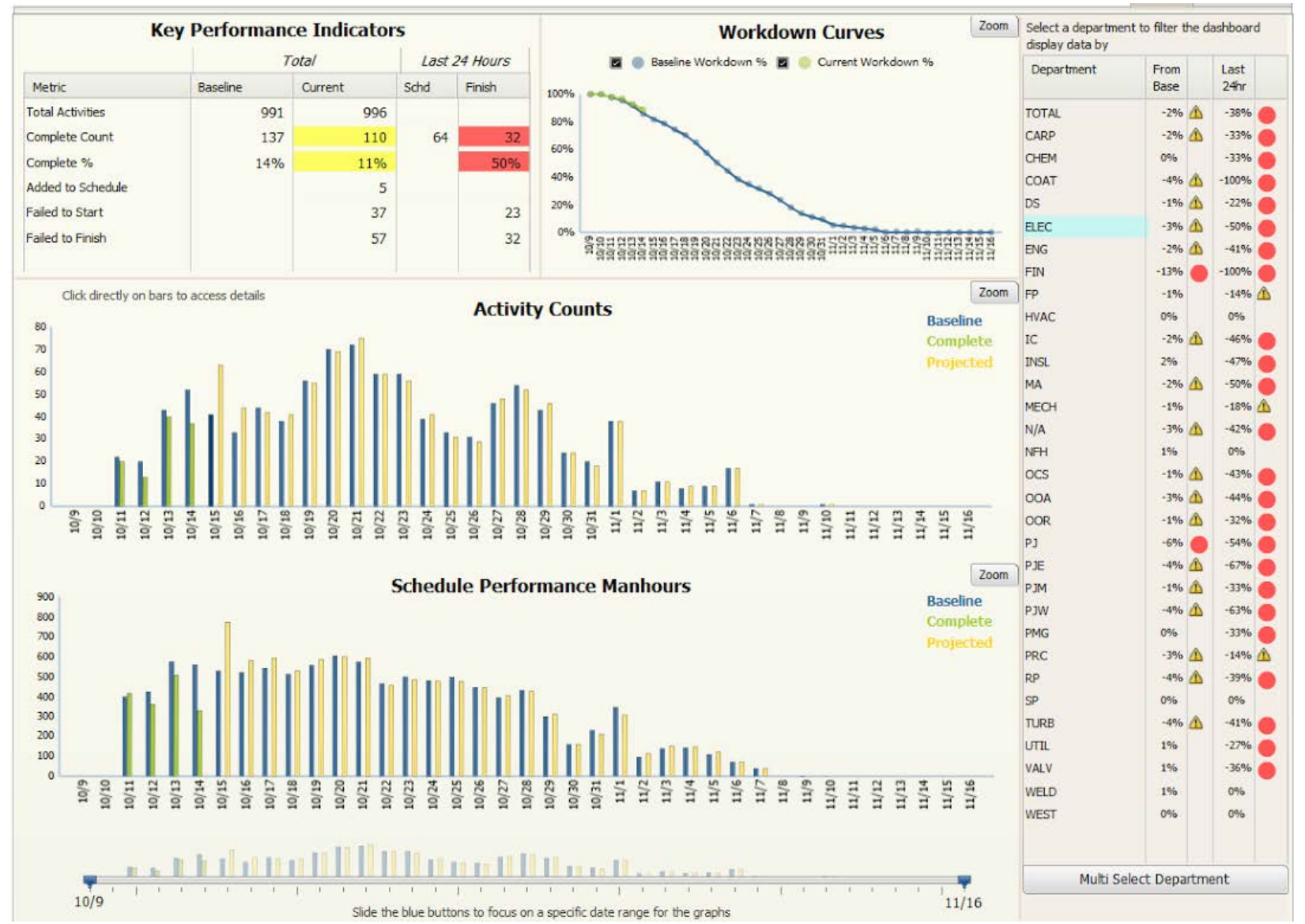

Figure 9. Example of utility outage dashboard.

\section{CONCLUSIONS}

This report presented the current status of improved graphical display concepts being developed for an AOCC. An AOCC is specifically designed to maximize the usefulness of communication and collaboration technologies for outage coordination and problem resolution activities. Central to the function of an OCC is the display of information. Currently, much of the information displayed in an OCC is static information printed on paper that the OCC staff manually updates. Schedule status information monitored in the OCC is typically the most crucial information needed to successfully execute the outage schedule. The OCC staff currently spends large amounts of time simply trying to determine the current status of work. Many nuclear utilities are in the process of implementing EWPs. The use of EWPs, combined with wireless technology, provides the capability to significantly improve outage management through access to real-time work status and enhanced coordination. For an AOCC to effectively take advantage of the benefits of EWPs, displays need developed to process this new data source. The use of software will allow analysis of this data and presentation of the impacts to the OCC staff. Currently, experienced outage staff is relied on to mentally process this information and determine these impacts.

HFE concepts may be used to ensure OCC displays are effective in supporting the OCC staff. This report summarized the most important human factors to consider related to OCC displays, both in the displays themselves, and the content presented. These considerations will help in the physical AOCC design and design of the individual displays in the AOCC. 
Outage work can be divided into two categories. The first category represents work that is on critical path, or near critical path. The second category represents bulk work, thousands of surveillances and preventive maintenance activities that must be accomplished during outage. To successfully complete an outage on schedule, both critical path and bulk work must be managed. To assist in managing critical path activities, a dynamic schedule monitor is being developed as part of the AOCC Pilot Project. The dynamic schedule monitor will use data from EWPs being performed in the field to provide a display for the OCC staff that automatically adjusts for schedule deviations. An early version of the dynamic schedule monitor was demonstrated at Palo Verde Nuclear Generating Station. While aimed at critical path work, the tool will also improve work package coordination, which will also assist in bulk work execution. Additional development of the dynamic schedule monitor will improve the usefulness of the displays to assist in understanding the impact of schedule deviations. To further assist in monitoring bulk work completion, future pilot project work will investigate application of big data analytics to outage information.

\section{REFERENCES}

EPRI, 2013, Improving the Execution and Productivity of Maintenance with Electronic Work Packages, EPRI, October 2013.

Hollifield, B., D. Oliver, I. Nimmo, and E. Habibi, 2008, The High Performance HMI Handbook, Houston: PAS.

ISO, 1999, "Human-Centered Design Processes for Interactive Systems," ISO 13407:1999, Section 7.3.2, International Organization for Standardization.

Kohn, Linda T., Janet M. Corrigan, and Molla S. Donaldson, 1999, "To Err is Human: Building a Safer Health System," Committee on Quality of Health Care in America, Institute of Medicine, National Academy Press: Washington, DC.

Wickens, C.D, J.D. Lee, Y. Liu, and S.E.G. Becker, 2004, An Introduction to Human Factors Engineering, Second Edition, Upper Saddle River, NJ: Prentice Hall. 